\title{
Ranking of mutual funds in Tehran Stock Exchange
}

\author{
Mohammadbagher Mohammadinejad Pashaki, Reza Tehrani, \\ Hamid Zarea, Hossein Khanifar, Gholamreza Jandaghi* \\ Faculty of Management and Accounting, Farabi Campus, University of Tehran, Iran \\ *E-mail address: jandaghi@ut.ac.ir
}

\begin{abstract}
Performance evaluation is one the most important point in investment therefore, in this research we tried to compute and compare the performance of mutual funds by different models and compare them to market. In this research, 14 active mutual funds during the year 2008 to 2012 has been chosen to calculate the risks and returns of these mutual funds and rank them. Results show that performance evaluation of modern and postmodern theory gives different ranking.
\end{abstract}

Keywords: Modern portfolio criteria; postmodern portfolio criteria; Mutual fund; Performance evaluation measures (sharp, trynor, sortino, omega)

\section{INTRODUCTION}

Managers and decision - makers are always judged by the results of their decisions. In one hand, organizational managers need to increase the capability and preciseness of their used models in order to respond dynamic conditions of today markets and taking effective decisions. Additionally, rapid economic and technological growth in recent decades have changed human life seriously and have faced modern societies with complicated decision making problems. Among financial and investment scenarios, investment in mutual funds is considered as a well - known financial strategy. Such funds tend to attract investors through diversification advantages, professional management, cash flow and economies of scale (Jabari et al, 2012). Mutual fund is a general title for investment companies with unfixed capital. Each mutual fund has its own investment policy expressed in its articles of association. For instance, money market investment funds use short term and low risk tools. Some funds are working in more limited fields (Bodie et al, 2008).

The paper by Harry Markowitz (1952) is recognized as the origin of modern portfolio theory. Modern portfolio theory is clarified by the relationship between computed return and risk through standard deviation while post modern portfolio theory clarifies the behavior of investor and the criterion to select the best portfolio through the relationship between return and undesired risk (Valezagherd \& Foladvandnya, 2010). 
Performance appraisal is important for investors. If the results of portfolio performance appraisal are not satisfactory, the reasons should be clarified in order to make necessary changes in investment policies. Portfolio appraisal is important whether someone investigates it personally or indirectly through in an investment company where he/she is capitalized. Performance appraisal of investment companies and ranking them are important since the dealers of these shares can take necessary measures on keeping, selling or purchasing the shares of these companies in required time. Naturally, potential investors are looking for those shares of investment companies that have better performance than other investment companies and also market performance. Performance appraisal means how investment manager can make a balance between returned and accepted risk (Islamibidgli et al, 2005). Research of evaluating the performance of investment funds and improving their investments can be a step to encourage more investment since a barrier against investment is investment risk(s) (Jabari et al, 2011).

The Research goals of this study are:

1. Ranking investment funds based on Sharp, Trynor, Omega and Sortino indices.

2. Comparing the performance of investment funds to market performance during surveyed period

3. Selecting a more precise measure for ranking among surveyed measures in present study

\section{BACKGROUND}

Abdeh Tabrizi and Sharifian (2008) studied the impact of undesired risk of mitigated performance based on the risk of admired investment companies in Tehran Stock Exchange. In this research, the relationship between ranking the companies based on Sharp criterion and desired potential was studied and they concluded that there is a relationship between them which is due to existence of negative skewness in return distribution. On this basis, using desired potential is more justified. Saeedi and Moghadasian (2010) evaluated the performance of investment funds by mitigated return based on their risks and using the criteria introduced by Sharp, Trynor, Sortino and Jensen. Based on results from ANOVA analysis, there is no significant difference between mitigated risk and market return. Likewise, no significant difference is seen between the performance of mutual investment funds based on the criteria by Sharp, Trynor and Sortino. However, differential return criterion by Jensen has not refused the existence of a significant difference between the performance of different investment funds in 2008 and 2008-2009 periods.

Roshangarzadeh and Ahmadi (2011) studied the performance of investment funds based on PMPT measures and the relationship between ranking them with MPT criteria. They concluded that there is significant relationship between MPT and PMPT criteria which is not due to return normal distribution rather it is due to the negative skewness of investment funds return. Therefore, the findings indicate the preference of postmodern criteria compared to modern ones.

Bertrand and Prigent (2011) studied the performance of two portfolio method guarantee which include portfolio guarantee strategies based on OBPI and CPPI by using undesired risk measure. To this end, they used indices by Kappa and Omega. Their findings indicate that CPPI has a better performance than OBPI. The following hypotheses have been tested in this study: 
$\mathrm{H}_{1}$ : Ranking mutual funds by indices of Sharp, Sortino, Trynor and Omega is not identical.

$\mathrm{H}_{2}$ : There is a significant relationship between mutual funds ranking based on total risk and downside risk.

\section{METHODOLOGY, DATA COLLECTION AND ANALYSIS METHOD}

In terms of goal, this is an applied study and in terms of methodology, it is a correlation - type descriptive study. Information on mutual funds return was collected by their websites as well as the reports by Stock Exchange and Securities Organization. After gathering relevant data, EXCEL software was used to compute data and SPSS was also utilized to test the hypotheses. To support or refuse data, deductive statistics were used. Statistical population of the research consists of mutual funds active in Tehran Stock Exchange between 2008 through 2011. Since the number of active investment funds in Tehran Stock Exchange is limited, all funds in the industry are analyzed as the sample provided that:

1. They are considered as active investment funds in Tehran Stock Exchange since the beginning of 2008 and are still in this list at the end of 2011 and their shares are dealt.

2. The data on these funds are available in the surveyed period (48 months). Therefore, those funds were deleted that lacked the conditions of paragraphs 1 and 2 .

The names of qualified mutual funds are as follows:

Arian mutual funds, Agah mutual funds, Eghtesad novin mutual funds, Pasargad mutual funds, Poya mutual funds, Hafez mutual funds, Khebregan mutual funds, Sahmashena mutual funds, Tejarat bank mutual funds, Saderat bank mutual funds, Melli bank mutual funds, Iranian kaspianmehr mutual funds, Yekom Iranian mutual funds, Pishtaz mutual funds.

\section{PORTFOLIO PERFORMANCE APPRAISAL INDICES}

Sharp index: according to average variance measure, Sharp (1966), Trynor (1965) and Jensen (1968) developed their famous performance measures. SP measures portfolio surplus return to risk free return rate divided on standard deviation (Naguez \& Prigent, 2011).

$$
S_{p}=\frac{R_{p}-R_{f}}{\delta_{p}}
$$

Treynor argued that a portfolio manager should be able to diversify and eliminate all the unsystematic risk. Once this is done the appropriate the measure of risk is the systematic which is measured through the beta. The performance measure proposed by Treynor is given by

$$
T_{p}=\frac{R_{p}-R_{f}}{b_{p}}
$$

where:

$T_{p}=$ treynor's portfolio performance measure for portfolio $\mathrm{p}$ over the evaluation period. 
$R_{p}=$ the average rate of return for portfolio $p$ over the evaluation period.

$R_{\mathrm{f}}=$ the average risk free return over the evaluation period.

$B_{p}=$ the beta of the portfolio over the evaluation period (Noulas et al 2005).

The sortino technique

One of the most popular measures is the sortino ratio .According to sortino and van der Meer (1991), calculating the return in excess of a minimum acceptance rate (MAR) would be more meaningful than calculating return in excess of a risk-free rate. They also note that downside risk ,not the total variability of returns, matters to investors. Thus, rather than dividing by the standard deviation of returns, the sortino ratio divides by the downside deviation of returns. Following equation shows the sortino ratio:

$$
\text { Sortino Ratio }=\left(\mathrm{R}_{\mathrm{p}}-\mathrm{MAR}\right) / \mathrm{DD}_{\mathrm{p}}
$$

where MAR is the minimum acceptable rate and $\mathrm{DD}_{\mathrm{p}}$ is the downside deviation of returns of the portfolio (Baker \& Filbeck, 2013).

Afterwards, Keating and Shadwick (2002) developed the performance measure omega, which divides the returns above the target rate of return by those below it. The omega measure $\Omega$ is defined as follows:

$$
\Omega(r)=\frac{\int_{r}^{b}[1-F(x)] d x}{\int_{a}^{r} F(x) d x}
$$

where $\mathrm{r}$ is the target rate of return, [a,b] is the interval of returns, and $\mathrm{F}(\mathrm{x})$ is the cumulative distribution of returns (Mamoghli \& Dabossi, 2009).

\section{DATA ANALYSIS AND RESULTS}

The first hypothesis addresses than whether the four indices show the same ranking of mutual funds. The result of testing the first hypothesis is shown in Table 1.

Table 1. Results of Friedman Test.

\begin{tabular}{cccc}
\hline & \multicolumn{3}{c}{ Results } \\
\hline $\begin{array}{c}\text { Number of } \\
\text { Observations }\end{array}$ & Chi-square & df & Sig \\
14 & 14.836 & 3 & 0.002 \\
\hline
\end{tabular}

Table 1 shows the significant difference between rankings based on the four indices. The second hypothesis states that there is significant relationship between rankings of mutual funds ranking based on total risk and downside risk. Table 2 shows the results. 
Table 2. Results of Spearman Correlation.

\begin{tabular}{ccc}
\hline & \multicolumn{2}{c}{ Results } \\
\hline Number of & Spearman & Sig \\
Observations & Correlation Coeff. & \\
14 & 0.60 & 0.023 \\
\hline
\end{tabular}

The Sig $=0.023$ shows the significant relationship between total risk and downside risk .

\section{CONCLUSIONS AND RECOMMENDATIONS}

Undoubtedly, providing fruitful information on funds and their performance appraisal can be an important step toward attracting and using individuals' effective capitals and directing them toward optimized institutes run by professional managers and members. To this end, evaluating the performance of these funds and comparing them to market return can help investors to select active and inactive investments. The first hypothesis showed the necessity of using various indicators on mutual funds' performance appraisal. Its findings are adaptive to the results by Rushangarzadeh and Ahmadi (2011). In the $2^{\text {nd }}$ and $3^{\text {rd }}$ hypotheses, the relationship between various ranking measures is addressed and the results revealed a strong relationship between modern and postmodern measures with each other. The reason is to use modern indices from similar factors such as standard deviation for risk and postmodern indices for similar factors such as undesired risk as the risk in postmodern measures. The $4^{\text {th }}$ hypothesis compares funds' return to market return. The results show difference between funds and market. These findings refuse the results by Saeedi and Moghadsian only due lower $\beta$ of Yekom Iranian' Fund than Market.

1. It is recommended that investors and analysts should not simply rely upon modern or postmodern measures and they should consider both measures in assessment factors.

2. It is recommended that investors and analysts should emphasis more on postmodern measures that provide more precise evaluation.

3. It is recommended that a similar research should be conducted with larger population and more indices and compared to present study.

4. Studies that investigate the performance result in more trustable findings when they are conducted in longer intervals. It is recommended to conduct a test in longer intervals.

\section{References}

[1] Abdeh Tabrizi Hussein, Sharifian Ruhollah, Stock Exchange Journal 1 (2008) 35-70.

[2] Baker H., Filbec G. (2013). Alternative investment, New jersey, John Wiley \& Sons.

[3] Bertrand P., Prigent J., Journal of Banking \& Finance 35(2013) 1811-1823.

[4] Bodie Z., Kane A., Marcus Alan J. (2008). Essentials of Investment, New York, McGraw-Hill Inc. 
[5] Jabari R., Salehi Sedghiani J., Amiri M., Research in Operation and its Applications Journal 9 (2011) 1-19.

[6] Mamoghli C., Daboussi S., The Journal of Wealth Management 12 (2009) 101-113.

[7] Naguez N., Prigent J., International Journal of Business 16(3) (2011) 207-217.

[8] Noulas A., Papanastasion J., Lazaridis J. (2005). Performance of mutual funds, Managerial finance, Number 2.

[9] Rushangarzadeh A., Ahmadi M. R., Financial Accounting Research Journal 1 (2011) 143-160.

[10] Saeedi A., Moghadasian I., Stock Exchange Quarterly 9 (2010) 5-24.

[11] Mohsen Mehrara, Hamid Abrishami, Mostafa Boroujli, Mahan Amin, International Letters of Social and Humanistic Sciences 11 (2013) 76-83.

[12] Bahram Meihami, Zeinab Varmaghani, Hussein Meihami, International Letters of Social and Humanistic Sciences 11 (2013) 91-99

[13] Mohsen Mehrara, Zabihallah Falahati, Nazi Heydari Zahiri, International Letters of Social and Humanistic Sciences 10(1) (2014) 26-35.

[14] Morteza Ziaee, International Letters of Social and Humanistic Sciences 10(1) (2014) 36-43.

[15] Gholamreza Jandaghi, Hamid Reza Irani, Ehssan Jandaghi, Zeinab Sadat Mousavi, Maryam Davoodavabi, International Letters of Social and Humanistic Sciences 15(1) (2014) 78-83. 